To cite this article: Kendirci HNP, Kaba İ, Comba A, Demir E.Çölyak hastalığı tanısı alan çocuklarda kemik mineral yoğunluğu ve kemik metabolizması belirteçlerinin değerlendirilmesi. Turk J Clin Lab 2020; 11: 107-110.

- Orjinal Makale

\title{
Çölyak hastalığı tanısı alan çocuklarda kemik mineral yoğunluğu ve kemik metabolizması belirteçlerinin değerlendirilmesi
}

\section{Evaluation of bone mineral density and bone metabolism markers in children diagnosed as celiac disease}

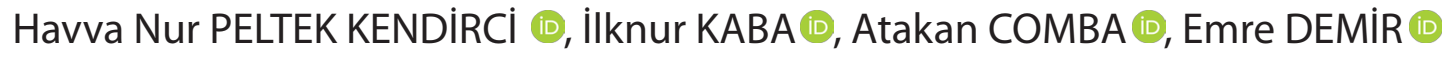

Hitit Üniversitesi Erol Olçok Eğitim Araştırma Hastanesi, Çocuk Sağlığı ve Hastalıkları Anabilim Dalı, Çorum/TÜRKiYE

Öz

Amaç: Çölyak hastalığında kalsiyum ve D vitamini eksikliğine bağlı metabolik kemik hastalığı en sık ekstraintestinal semptomlardan biridir. Bu çalışmada, çölyak hastalığı olan çocuklarda tanı esnasında kemik mineral yoğunluğunun değerlendirilmesi ve kemik mineral metabolizmasıyla ilişkili faktörlerin değerlendirilmesi amaçlandı.

Gereç ve Yöntemler: Çalışmaya hastanemiz çocuk gastroenteroloji bölümünde Aralık 2015-Aralık 2019 tarihleri arasında çölyak hastalığı tanısı alan 43 çocuk hasta alındı. Retrospektif olarak hastaların klinik, antropometrik, patolojik ve laboratuar özellikleri [kalsiyum, fosfor, alkalenfosfataz (ALP), parathormon (PTH), 25-OH vitamin D düzeyleri] incelendi. Tanıda Dual Energy X-Ray Absorptiometry (DEXA) yöntemi ile ölçülmüş olan lumbal (L1-L4) kemik mineral yoğunluğu düzeyleri değerlendirilerek kronolojik yaşa ve boy yaşına göre Z-skorları hesaplandı.

Bulgular: Ortalama yaşları 9,9 $\pm 4,8(2,5-17,7)$ yıl olan 43 hastanın (34 kız/9 erkek) verileri değerlendirildi. \%30,2'si ( $n=13$ )

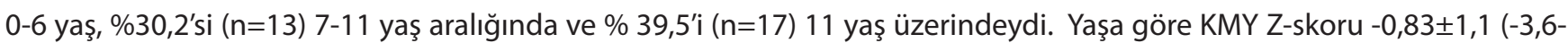
$1,6)$, boy yaşına göre KMY Z-skoru -0,18 $\pm 1,1(-3,6-1,8)$ saptandı. Hastaların $\% 51,2$ 'sinde $(n=22)$ yaşa göre KMY Z-skoru>-1, $\% 34,9^{\prime}$ unda ( $\left.n=15\right)$-1 ve -2 arasında ve \%14'ünde $(n=6)<-2$ saptandı. Yaşa göre KMY Z-skorunun<-2 olma oranı 11 yaştan büyük çocuklarda anlamı olarak yüksekti $(p<0,001)$. Hastaların KMY Z-skorları ile serum D vitamini, kalsiyum, fosfor, ALP ve PTH düzeyleri arasında ilişki saptanmadı $(p>0,050)$.

Sonuç: Çölyak hastalarında tanı yaşının gecikmesi kemik mineral yoğunluğunu olumsuz etkilemektedir. Erken yaşta tanı konulması kemik mineral kaybını engeller ve osteopeni/osteoporoz gelişmiş olan hastalarda tedavi olanağı sağlayarak morbiditeyi azaltır.

Anahtar kelimeler: çocuk; çölyak hastalığı;kemik mineral yoğunluğu

\footnotetext{
Sorumlu Yazar*: Ilknur Kaba, Hitit Üniversitesi Erol Olçok Eğitim Araştırma Hastanesi, Çocuk Sağlığı ve Hastalıkları Anabilim Dalı, Çorum/TÜRKiYE E-posta: ilknurkaba@yahoo.com

ORCID: 0000-0003-0969-7548

Gönderim: 17.01.2020 Kabul: 09.05.2020

Doi: 10.18663/tjcl.676391
} 


\section{Abstract}

Aim: Metabolic bone disordersduetocalsiumand vitamin D deficiencyareone of themostfrequentextraintestinalsymptoms in Celiacdisease. In this study it is aimed toevaluate bone mineral density in patients with Celiacdisease duringdiagnose and evaluatethe factors related to bone mineral metabolism.

Material and ethods: The study included 43 children diagnosed as Celiacdisease between December 2015 and December 2019. Clinical, anthropometric, pathological and laboratory (calsiyum, phosphor, alkalenphosphataz (ALP), parathormon (PTH), 25OHvitamin D levels) properties of patients were detected retrospectively. Lumbal (L1-L4) bone mineral densityleve Ismeasuredvia DEXA (Dual Energy X-Ray Absorptiometry) were evaluatedand Z scoresduetocronologicalageandheightagewerecalculated.

Results: Meanage of 43 patients ( 34 girl/9 boys) was $9.9 \pm 4.8$ (2.5-17.7) years. $30.2 \%(n=13)$ was $0-6$ years old, $30.2 \%(n=13)$ was 7-11 years and $39.5 \%(n=17)$ wasover 11 years. BMD Z scoreduetochronologicalage was $-0.83 \pm 1.1(-3.6-1.6)$ and $-0.18 \pm 1.1(-3.6-1.8)$ duetoheight age. BMD Z scoresduetochronologicalagewas $>-1$ in $51.2 \%$ of thepatients $(n=22)$, between -1 and -2 in $34.9 \%(n=15)$ and $<-2$ in $14 \%(n=6)$. BMD Z scoresduetochronologicalage $<-2$ in over 11 age was statistically high $(p<0.001)$. No relation between BMD Z scoresandplasma vitamin $D, C a, P, A L P$ and PTH levels $(p>0.050)$.

Conclusion:Delayed diagnoseageseffects bonemineral densitynegatively in Celiacdisease.Diagnose in earlyagesdecreases bone mineral leakanddecreasesmorbidity in patients with osteopeniandosteoporosisviatreatmentposibilities.

Keywords: child; celiacdisease; bone mineral density

\section{Giriş}

Çölyak Hastalığı genetik duyarlılığı olan bireylerde farklı klinik görünümlerde ortaya çıkan, çocukluktan erişkin döneme uzanan geniş bir yaş aralığında tipik ve atipik bulgular ile seyreden, ince bağırsaklardaglutene karşı anormal immün yanıt sonucu gelişen bir hastalıktır [1,2].Çölyak hastalığında(ÇH) ekstra intestinal bulgular büyük oranda proksimal emilim bozukluğuna bağlı oluşmaktadır. Günümüzde ishal, karın şişliği, iştahsızlık gibi hastalık belirtileri gittikçe daha az görülmekte olupatipikçölyak hastalığı daha sık görülmektedir[3].

Çölyak hastalığında büyüme geriliği, puberte gecikmesi, tedaviye dirençli demir eksikliği anemisi, D vitamini eksikliği, kalsiyum eksikliğine bağlı metabolik kemik hastalığı, erken yaşta osteopeni ve osteoporozuile gelebilmektedir. ÇH'yebağlı düşük kemik mineral yoğunluğu, ince barsaktak iinflamasyonasekonder gelişen intestina Imalabsorpsiyonsonucu kalsiyum ve vitamin D eksikliğinden kaynaklanmaktadır[3,4]. Düzleşmiş mukozadan kalsiyum ve $D$ vitamini emiliminin bozulmasına, endojen kalsiyum kullanımının artmasına veya dışkı ile kaybedilmesine bağlı, negatif kalsiyum dengesi ve parathormon (PTH)'nunkompansatuar yanıtı kemik kaybının esas nedenidir. Kemik ağrıları, yalancı kırıklar ya da kemik deformiteleri olabileceği gibi osteomalazi durumunda genellikle semptom görülmez. Bu nedenle yeni tanı konulan hastalarda kemik mineral yoğunluğu(KMY) ölçümü yapılmalıdır[5].
Çalışmamızın amacı, ÇH tanısı alan çocuklarda tanı esnasında KMY belirlenmesi ve kemik mineral metabolizmasıyla ilişkili faktörlerin araştırılması amaçlanmıştır.

\section{Gereç ve Yöntemler}

Çalışmaya Aralık 2015-Aralık2019 tarihleri arasında hastanemiz çocuk gastroenteroloji polikliniğinde çölyakhastalığıtanısı alan hastalar dahil edildi. Çalışma Helsinki Illkeler Deklerasyonu'na uyularak gerçekleştirildi ve Hitit Üniversitesi Tıp Fakültesi Etik Kurulu'ndan onay alındı (11.12.2019/109).

Çölyak hastalığı tanısı Avrupa Çocuk Gastroenteroloji Hepatoloji ve Beslenme Derneği (ESPGHAN) 2012 kriterlerine göre kondu [6]. İnce bağırsak biyopsilerinin histopatolojik değerlendirmesi modifiye Marsh (Oberhuber) sınıflaması ile yapıldı [7]. Retrospektif olarak hastaların hastane bilgi yönetim sistemine kayıtlı klinik, antropometrik, patolojik ve laboratuarverileri [kalsiyum, fosfor, alkalenfosfataz (ALP), parathormon (PTH), $25 \mathrm{OH}$ vitamin $\mathrm{D}$ düzeyleri] incelendi. HastalarınHolojic DXA Quality Control Phantom marka alet ile DEXA yöntemiyle ölçülmüş olan lumbal (L1-L4) kemik mineral yoğunluğu düzeyleri değerlendirildi ve kronolojik yaşa ve boy yaşına göre KMY Z-skorlarının hesaplanmasında sağlıklı Türk çocuklarının KMY verileri kullanıldı[8]. Hastaların boy, vücut ağırlığı ve vücut kitle indekslerinin (VKI) değerlendirilmesinde ve bu ölçümlerin standart deviasyon skorlarının (SDS) hesaplanmasında Neyzi ve arkadaşları tarafından Türk 
çocukları için hazırlanmış olan persentil çizelgeleri referans alındı [9]. Cinsiyete göre çocuğun boyunun 50. persentildeki yaş karşıı̆ı̆ıboy yaşı olarak kabul edildi.

İstatistiksel analizler IBM SPSS Statisticsfor Windows 22.0 yazılımı ile gerçekleştirildi Nitel değişkenleri karşılaştırmak için Pearson ki-kare testi ya da beklenen frekansı 5 'ten küçük hücre olduğunda Fisher'in kesin testi kullanıldı. Sayısal değişkenlerin normal dağılım gösterip göstermediği Shapiro-Wilk testi ile incelendi, normal dağılan değişkenleri 2 grupta karşılaştırmak için bağımsız gruplarda t-testikullanıldı. Normal dağı̆lmayan değişkenleri 2 grupta karşılaştırmak için Mann-Whitney U testi kullanıldı. Normal dağılan değişkenler arasındaki ilişki Pearson bağıntı katsayısı ve normal dağılmayan değişkenler arasındaki ilişki ise Spearman sıra bağıntı katsayısı kullanılarak incelendi. $p<0,05$ değeri istatistiksel olarak anlamlı kabul edildi.

\section{Bulgular}

Ortalama yaşları 9,9 $9 \pm 4,8(2,5-17,7)$ yıl olan 43 hastanın ( 34 kız/9 erkek) verileri değerlendirildi. Tanıda hastaların $\% 46,5^{\prime} i(n=20)$ pubertaldi. Olguların klinik özellikleri Tablo 1'de, laboratuar özellikleri Tablo 2'de gösterilmiştir.

\begin{tabular}{|c|c|c|}
\hline & Ortalama $\pm S D$ & En küçük-En büyük \\
\hline Yaş (yıl) & $9,9 \pm 4,8$ & $2,5-17,7$ \\
\hline Vücut Ağırlığı (kg) & $29,9 \pm 14,6$ & $11,4-65,5$ \\
\hline Vücut Ağırlığı SDS & $-1,1 \pm 1,1$ & $-3,5-0,8$ \\
\hline Boy $(\mathrm{cm})$ & $130,0 \pm 27,0$ & $86,5-178,3$ \\
\hline Boy SDS & $-0,9 \pm 1,3$ & $-4,2-1,9$ \\
\hline VKi (kg/m2) & $16,4 \pm 2,1$ & $12,9-22,4$ \\
\hline VKI SDS & $-0,8 \pm 1,1$ & $-3,1-1,0$ \\
\hline Puberte evresi (median) & 1 & $1-5$ \\
\hline
\end{tabular}

\begin{tabular}{lcc} 
Tablo 2. Olguların laboratuar özellikleri & \\
& Ortalama + Standartdeviasyon & $\begin{array}{c}\text { En küçük- } \\
\text { En büyük }\end{array}$ \\
\hline Kalsiyum (mg/dl) & $9,7 \pm 0,4$ & $8,9-10,9$ \\
\hline Fosfor $(\mathrm{mg} / \mathrm{dl})$ & $4,7 \pm 0,6$ & $2,7-6,0$ \\
\hline Alkalenfosfataz $(\mathrm{U} / \mathrm{L})$ & $203,0 \pm 100,1$ & $100,0-466,0$ \\
\hline Parathormon(pg/ml) & $45,0 \pm 21,5$ & $19,6-109,3$ \\
\hline 25 OH vit D $(\mathrm{ng} / \mathrm{ml})$ & $13,5 \pm 7,7$ & $4,6-35,1$ \\
\hline
\end{tabular}

Hastaların ortalama KMY düzeyi $0,6 \pm 0,2(0,3-1,0) \mathrm{gr} / \mathrm{cm} 2$ olup, yaşa göre KMY Z-skoru -0,83 $\pm 1,1(-3,6-1,6)$, boy yaşına göre KMY Z-skoru -0,18 $\pm 1,1 \quad(-3,6-1,8)$ saptandı. Hastaların $\% 51,2$ 'sinde $(n=22)$ yaşa göre KMY Z-skoru >-1, \%34,9'unda $(n=15)-1$ ve -2 arasında ve $\% 14$ ünde $(n=6)<-2$ saptandı.

Olguların \%30,2'si ( $n=13$ ) 0-6 yaş, \%30,2'si ( $n=13$ ) 7-11 yaş aralığında ve \% 39,5'i $(n=17) 11$ yaş üzerindeydi. Yaşa göre KMY Z-skorunun<-2 olma oranı 11 yaştan büyük çocuklarda anlamı olarak yüksekti $(p<0,001)$ (Tablo 3 ).

\begin{tabular}{|c|c|c|c|}
\hline \multicolumn{4}{|c|}{ yaşa göre KMY Z skorları dağılımı } \\
\hline \multirow[b]{2}{*}{ Yaş grubu } & \multicolumn{3}{|c|}{ Yaşa Göre KMY Z-skoru } \\
\hline & $<-2$ & -1 ve -2 arası & $>-1$ \\
\hline $0-6 y$ & $\% 0(n=0)$ & $\% 53,8(n=7)$ & $\% 46,2(n=6)$ \\
\hline 7-11 yaş & $\% 0(n=0)$ & $\% 46,2(n=6)$ & $\% 53,8(n=7)$ \\
\hline 11 yaş $(n=17)$ & $\% 35,3(n=6)$ & $\% 11,8(n=2)$ & $\% 52,9(n=9)$ \\
\hline
\end{tabular}

Hastaların \%16,7'si ( $n=7)$ tipik, \%64,3'ü ( $n=28)$ atipik ve \%19'u $(n=8)$ sessiz ÇH idi. Marsh evresine göre ise, \%46,5'i $(n=20)$ Tip 3a, \%25,6'sı ( $n=11)$ Tip 3b, \%27,9'u ( $n=12)$ Tip 3c olarak saptandı.KMY Z-skorları ile çölyak tipi ve Marshhistopatolojik evresi arasında ilişki saptanmadı $(p>0,050)$.

Hastaların yaşı ve puberte durumu ile kronolojik yaşa göre ve boy yaşına göre KMY Z-skorlarında farklııık saptanmadı (sırasıyla $p=0,150, p=0,225)$. Yaşa göre KMY Z-skoru ile vücut ağırlığı, boy ve VKI SDS arasında pozitif korelasyon saptandı (sırasıyla $r=0,574 ; p<0,001, r=0,420 ; p=0,005, r=0,368 ; p=0,015)$.

Hastaların yaşa ve boy yaşına göre KMY Z-skorları ile serum $D$ vitamini, kalsiyum, fosfor, ALP ve PTH düzeyleri arasında ilişki saptanmadı $(p>0,050)$.

\section{Tartışma}

Çölyak hastalığı hem çocuklarda hem de erişkin yaş grubunda görülen ve yaşam boyu devam eden bir hastalıktır ve çok geniş bir yelpazede klinik bulgularla karakterizedir. Erken yaş grubunda ishal, karın şişliği, büyüme geriliği gibi tipik belirtiler ön planda iken, yaş ilerledikçe osteoporoz, malignite, epilepsi vs. gibi gastrointestinal sistem dışı belirtiler ön plana geçer [10]. Düşük kemik mineral yoğunluğu tedavi edilmemiş çölyak hastalarında önemli bir komplikasyondur. Çölyak hastalığınabağlı düşük kemik mineral yoğunluğu, intestinalmalabsorpsiyona bağlı gelişen kalsiyum ve $D$ vitamini eksikliğinden kaynaklanmaktadır.Osteoporoz, rikets ve osteomalazi, ÇH'nınatipik bulgularındır[5,11]. Tedavisiz hastalarda KMY'nun normalden düşük olduğu, sıkı glutensiz diyet tedavisi ile hızla normale döndüğü gösterilmiştir [5]. Medave arkadaşlarının yaptığı çalışmada KMY ölçümü yapılan 41 hastadan \%22'sinde osteopeni, \%12.2'sinde osteoporoz ve ayrıca iki hastada rikets $(\% 14,3)$ saptanmıştır [5]. Tau ve arkadaşlarınınçalışmasında yaşları 1-11 arasında değişen 24çölyak tanılı hastaya yapılan lombervertebra DEXA ölçümünde $Z$ skoru değerlerinin oldukça düşük olduğu $(-1.36 \pm 1.20)$ ve olguların \% 17'sinin Z skorunun -2'den daha düşük olduğu ortaya çıkmıştır bulunmuştur[3]. Zanchi ve ark. tedavisiz 54 çölyaklı çocukta yaptıkları DEXA taramasında \%18 oranında osteopeni (Z skoru -2 SD ile -1 SD arası) tespit ettiler [12]. Altıaylık glutensiz diyet sonrasında ise hastaların kemik 
mineral yoğunluğunda iyileşme olduğunu, bu nedenle çölyak hastalığı olan ve glutene kısa süre maruz kalmış çocuklarda kemik metabolizması için ileri tetkiklerin gereksiz olduğunu belirtmişlerdir[12,13]. Çalışmamızda ise \%34,9 oranında osteopeni ve \%14 oranında osteoporoz saptandı.

Tanıda, Marshhistopatolojik evresinin osteoporoz gelişme riski taşıyan düşük KMY oluşumunu tahmin edebileceği öne sürülmektedir. Öte yandan tanı anında hastaların KMY'nunMarsh derecesiyle ilişkili olmadığını ve ÇH olan çocuklarda düşük KMY için klinik ve laboratuar belirteçlerin olmadığını ileri süren çalışmalar da mevcuttur[14]. Çalışmamızda KMY Z-skorları ile Marshhistopatolojik evresi arasında ilişki saptanmadı.

Balcı ve ark.tarafından yapılan çalışmada, çalışmamıza benzer şekilde ÇH tanısı almış hastalarda KMY Z-skorları ile serum kalsiyum, D vitamini, parathormon vediyetle kalsiyum alımı arasında anlamlı bir farklılık bulamamışlardır [14]. Çölyak hastalığı ilişkili osteoporozla ilgili önemli nokta, glutensiz diyet tedavisi ile KMY'da tam iyileşme çocuklarda mümkünken, bu durumun yetişkinler için geçerli olmamasıdır [14,15]. Literatürde çölyak hastalığı olan çocuklarda yaş arttıkça KMY Z-skorlarında azalma olduğu ve yaş ile orantısal olarak kemik mineral kaybının arttığını bildirilmiştir. Çalışmamızda da benzer şekilde yaşa göre KMY Z-skorunun<-2 olma oranının 11 yaştan büyük çocuklarda anlamı olarak yüksek olduğu saptandı. Sıkı glütensiz diyetin kemik mineralizasyonunu önemli ölçüde artırdığı vurgulanmaktadır[16]. Ergenlikten önce uygun tedaviyi alan hastaların yetişkin yaşlarda osteoporotik hale gelmeyecekleri bildirilmektedir [14].

\section{Sonuç}

Çölyak hastalarında tanı yaşının ileri kayması kemik mineral yoğunluğunu olumsuzetkilemektedir. Erken yaşta tanı konulması kemik mineral kaybını engeller ve osteopeni ve / osteoporoz gelişmiş olan hastalarda tedavi olanağı sağlayarak morbiditeyi azaltır.Bu durum, hastaların erken teşhis ve tedavisini gerekli kılmaktadır.

\section{Çıkar çatışması / finansal destek beyanı}

Bu yazıdaki hiçbir yazarın herhangi bir çıkar çatışması yoktur. Yazının herhangi bir finansal desteği yoktur.

\section{Kaynaklar}

1. Ravikumara M, Tuthill DP, Jenkins HR. Clinical presentation of coeliac disease. Arch Dis Child 2006; 91: 969-71.

2. Troncone R, Jabri B. Celiac disease and gluten sensitivity. J Intern Med 2011; 269: 582-90.
3. Tau C, Mautalen C, De Rosa S, Roca A, Valenzuela X. Bone mineral density in childrenwithceliacdisease. Effect of a Gluten-freediet. Eur J ClinNutr 2006; 60: 358-63.

4. Tahiri L, Azzouzi H, Squalli G, Abourazzak F, Harzy T. Celiac disease causing severe osteomalacia: an association stil present in Morocco! Pan Afr Med J 2014;19:43.

5. Meda Kondolot, Fulya Demirçeken, Ülker Ertan. 52 vaka ile Türk çocuklarında çölyak hastalığı. Türkiye Çocuk Hastalıkları dergisi 2009; 3:10-17

6. Husby S, Koletzko S, Korponay-Szabó IRet al. European society for pediatric gastroenterology, hepatology, and nutrition guidelinesfor the diagnosis of coeliac disease.J Pediatr Gastroenterol Nutr 2012;54:136-160

7. Oberhuber G, Granditsch G, Vogelsang H. The histopathology of coeliac disease: time for a standardized reports cheme for pathologists. Eur J Gastroenterol Hepatol 1999;11: 1185-94.

8. GoksenD, Darcan Ş, Coker M, KoseT . Bone Mineral Densitometry Findings of $C$ with Newly Diagnosed Celiac Disease. Molecular Imaging and RadionuclideTherapy 2011;20: 59-62

9. Neyzi O, Günöz H, Furman H .Türk Çocuklarının vücutağırlığı, boy uzunluğu, baş çevresi ve vücut kitle indeksi referans değerleri. Çocuk Sağlığı ve Hastalıkları Dergisi 2008;51:1-14

10. Fasano A, Catassi C. Current approaches to diagnosis and treatment of celiac disease: an evolving spectrum. Gastroenterology 2001; 120: 636-51

11. Demirçeken FG, Kansu A, Kuloğlu Z, Girgin N, Güriz H, Ensari A. Human tissue transglutaminase antibody screening by immunochromatographic line immunoassay for early diagnosis of celiac disease in Turkish children. Turk J Gastroenterol 2008; 19:14-2

12. Zanchi C, Dileo G, Ronfani L, Martelossi S, Not T, Ventura A, Bone metabolism in celiacdisease. J Pediatr 2008; 153: 262-65.

13. Ayhan Gazi Kalayci. Bone Mineral Density and Importance of a Gluten-Free Diet in Patients With Celiac Disease in Childhood Pediatrics November 2001, 108.

14. BalcIT, KoçZP, Mitil HA. Bone mineral density of healthy Turkish children and adolescents. Journal of Clinical Densitometry2006; 9: 84-90,

15. Fernández $\mathrm{CB}$, Moreiras GV, Úbeda $\mathrm{N}$, Alonso-Aperte $\mathrm{E}$. Nutritional status in spanish children and adolescents with celiac disease on a gluten free diet compared to non-celiac disease controls. Nutrients 2019;1:11.

16. Choudhary G, Gupta RK, Beniwal J.Bone mineral density in celiac diseaselndian j pediatr 2017; 84: 344-48. 